\title{
Prestasi Pusat Pendidikan Dan Latihan Olahraga Mahasiswa (PPLM) Provinsi Bali
}

\author{
Made Agus Dharmadi \\ Universitas Pendidikan Ganesha, Singaraja \\ *Corresponding author: made_agus2011@ hotmail.com
}

\section{A R T ICLE INFO}

Article history:

Received 20 June 16

Received in revised form 12 July 16

Accepted 05 August 16

Keywords:

The Sport Achievement; Pusat

Pendidikan dan Latihan Olahraga;

Mahasiswa/PPLM; Evaluation

\begin{abstract}
A B S TR A C T
The aim of this study is to evaluate the sport achievement at Students Sport Training and Education Centre (Pusat Pendidikan dan Latihan Olahraga Mahasiswa/PPLM) at Bali Province. It is a qualitative research with evaluation approach. The data collection method by triangulation uses interview, document study, and observation fields. Based on the data analysis it can be summarized 1) The Students Sport Training and Education Centre at Bali Province improving the athletes' physiscal fitness, 2) The Students Sport Training and Education Centre at Bali Province improving the athletes' techniques, 3) various number and fluctuative medal achievement in sport championships but tend to decline. Based on the result, it can be recommended that the program PPLM Bali is still feasible to proceed, but need some management improvemen to enhance the achievement.
\end{abstract}

\section{Pendahuluan}

Sebagai bangsa yang tergolong ke dalam kelompok negara berkembang, dimana penduduknya masih diliputi suasana meningkatkan pertumbuhan taraf hidup yang lebih baik, maka olahraga sebagai bidang kajian saat ini nampaknya belum mendapatkan prioritas utama, sehingga bisa dikatakan pertumbuhan olahraga belum menggembirakan, padahal kemampuan fisik sangatlah berperan dalam hubungannya dengan kesehatan (Gutierrez,2007). Hal ini diikuti dengan masih sangat terbatasnya tempat-tempat berolahraga di lingkungan lembaga pendidikan, lingkungan pemukiman dan lingkungan industri, bahkan banyak lapangan olahraga yang telah ada beralih fungsi, sehingga tidak lagi dapat digunakan untuk berolahraga (Cholik \& Maksum, 2007).

Tantangan di atas merupakan identifikasi permasalahan dalam upaya memunculkan usaha-usaha perbaikan ke arah yang lebih baik. Pemerintah menyadari untuk mencapai prestasi di bidang olahraga tidak bisa diraih dengan mudah dan dengan jalan pintas, mesti dilakukan upaya-upaya yang komprefensif dan terpadu, baik dari sisi pendanaan, pembinaan, sarana dan prasarana, pembibitan dalam hal ini, parameter kinematik sangat penting dalam hal mendiagnosa bakat olahraga (Mattes, Hebermann, Schaffert \& Muhlbach, 2014). Tidak terlepas pula peran keluarga, dimana keluarga yang aktif berolahraga akan menumbuhkan budaya olahraga bagi anaknya, orangtua harus menjad model bagi anaknya (Marques, Martins, Sarmento, Diniz, \& Da Costa, 2014).

Kehadiaran PPLP dan PPLM dimaksudkan sebagai salah satu sistem pembinaan olahraga prestasi sekaligus pembibitan yang terpadu, berkelanjutan dan berjenjang (UU SKN, 2005), sehingga setelah lulus menjadi pelajar akan di bina kembali saat menjadi mahasiswa melalui PPLM. PPLM merupakan salah satu pusat pembinaan atlet tingkat mahasiswa yang penanganannya diserahkan pada perguruan tinggi yang membina fakultas olahraga. Adanya PPLM sangatlah berperan dalam upaya mewujudkan cita-cita pemerintah dalam melaksanakan pembinaan yang berjenjang dan berkelanjutan sehingga lulusan atlet PPLP dapat di wadahi di PPLM, yang tujuan akhirnya adalah untuk mencapai prestasi yang maksimal baik di tingkat nasional maupun internasional.

PPLM merupakan sekolah pembibitan olahraga nasional, yang digunakan untuk mencari dan membina bakat olahraga pada usia mahasiswa. Hal ini sesuai dengan salah satu upaya mewujudkan olahraga yang berdaya saing, sehingga peran pembibitan, pembinaan, pendidikan, pelatihan serta peningkatan prestasi olahraga yang berkelanjutan menjadi sangat sentral. Untuk itu, pemerintah telah memiliki program 29 PPLM di 26 provinsi yang ada di Indonesia tidak lain agar tujuan utama bidang keolahragaan di atas dapat tercapai (Kemenpora,2013).

Dengan terbentuknya PPLM, diharapkan; 1) atlet-atlet mahasiswa yang tergabung secara fisik dan psikologis telah memasuki usia emas dan prestasi puncak, 2) sistem pembinaan dapat dilakukan secara sistematis menggunakan pendekatan keilmuan, 3) dapat ditangani oleh pelatihpelatih lulusan perguruan tinggi maupun pengurus daerah/cabang olahraga sesuai dengan pengalaman dan kualifikasi di bidangnya, 4) menjalin hubungan kerjasama dengan kalangan akademisi atau pakar dari berbagai perguruan tinggi.

Sejauh ini, program PPLM Bali telah berjalan hampir 10 tahun, namun prestasi yang diperoleh terkesan menurun dari tahun ketahun. Oleh karena itu evaluasi product PPLM Bali sangat dibutuhkan saat ini, sehingga prestasinya dapat ditingkatkan.

Bertitik tolak dari hal tersebut di atas, maka dalam upaya meningkatkan prestasi PPLM Bali melalui sistem pengelolaan, sistem pelatihan dan sistem manajerial yang baik, sangat dipandang urgent untuk dilakukannya evaluasi product Program PPLM Bali, sehingga penelitian ini yang berjudul "Prestasi Pusat Pendidikan dan Latihan Olahraga 
Mahasiswa (PPLM) Provnsi Bali” menjadi sangat penting untuk dilakukan.

\section{Metode}

Penelitian ini dilaksanakan di Pusat Pendidikan dan Latihan Olahraga Mahasiswa Bali tahun 2014/2015. Sampel penelitian dipilih secara purposive atau berdasarkan tujuan penelitian yang berjumlah 20 orang alumni atlet PPLM Bali (Usman \& Purnomo,2008). Hal ini dimaksudkan untuk mengambil subjek yang benar-benar mengetahui dan memahami tentang objek yang diteliti sehingga data yang dicari dapat diperoleh sesuai dengan tujuan penelitian dan mudah dicari maknanya (Arikunto \& Jabbar, 2009). Pendekatan penelitian ini adalah penelitian kualitatif dengan pendekatan evaluasi (Stufflebeam, \& Anthony, 2007). Teknik pengumpulan data dilakukan secara triangulasi melalui observasi berperan serta, wawancara mendalam dan dokumentasi

Analisis data yang digunakan dalam penelitian ini adalah analisis deskriptif kualitatif, yaitu dengan mendeskripsikan dan memaknai data dari indikator komponen yang dievaluasi (Subana \& Sudrajat, 2005). Menurut Miles dan Hubberman dalam Patilima (2005), analisis data terdiri dari tiga jalur kegiatan yang dilakukan secara bersamaan yaitu; reduksi data, penyajian data dan penarikan kesimpulan. Tahap analisis data dalam penelitian ini, diawali dengan pengumpulan data yang merupakan proses melakukan pengumpulan berbagai data penelitian, selanjutnya dilakukan reduksi data yang merupakan proses pemilihan, pemusatan perhatian dan penyederhanaan data, teori dan metode dalam bentuk uraian rinci dan sistematis untuk mengemukakan hal-hal yang dianggap penting (Silalahi,2010).

\section{Hasil dan Pembahasan}

Penelitian ini ditekankan pada evaluasi prestasi olahraga Pusat Pendidikan dan Latihan Olahraga Mahasiswa (PPLM) Bali yang menggunakan pendekatan model evaluasi pada komponen Product Hasil evaluasi Product terdiri dari peningkatan kebugaran fisik, keterampilan dan prestasi yang diperoleh PPLM Bali kurun waktu tahun 2007-20014 adalah sebagai berikut:

\section{A. Kebugaran Fisik}

Hasil dari suatu proses tersebut dapat berupa peningkatan kebugaran fisik, peningkatan keterampilan dan juga budaya mental yang positif. Berdasarkan wawancara dengan pelatih, mantan pelatih, atlet dan alumni atlet PPLM Bali, terungkap bahwa peningkatan dari sisi fisik cukup dirasakan oleh atlet, dan hanya sedikit yang menyatakan kebugarannya masih tetap seperti semula. Adapun hasil wawancara sebagai berikut: "Peningkatan fisik untuk atlet yang saya latih tentu saja meningkat, ini terlihat dari kemampuan mereka dalam menjalani sesi latihan setiap harinya yang semakin bugar dan tidak mudah lelah, peningkatannya sekitar $10-20 \%$ tergantung motivasi atletnya" (Ni Putu Spyanawati, Pelatih Pencak Silat).
"PPLM mampu menigkatkan kemampuan saya, baik fisik maupun teknik, adanya kejuaraan juga mampu mengasah fisik dan teknik juga mental kita" (Sukariata, Alumni ATlet Atletik, Tahun 2006-2009).

"Kebugaran fisik saya meningkat sedikit, beda pada waktu saya di PPLP yang rutin latihan sore harinya karena sekolah pagi aja. Kalau di PPLM kuliah pagi dan sore, tugas lumayan banyak. Dulu pernah ada MFT level 9,8 namun sekarang agak susah payah mencari level tersebut" (Atlet Pencak Silat).

Berdasarkan hasil wawancara, studi dokumen dan studi lapangan dapat disimpulkan bahwa atlet PPLM di Bali mengalami peningkatan perkembangan fisik dengan cukup baik, namun perlu adanya upaya memotivasi atlet agar berlatih dengan keras serta mampu menyesuaikan diri dengan tugas-tugas akademik sebagai mahasiswa.

\section{B. Keterampilan Teknik}

Hasil dari suatu proses tersebut dapat berupa peningkatan kebugaran fisik, peningkatan keterampilan dan juga budaya mental yang positif. Pada tataran keterampilan teknik, peningkatan keterampilan. Adapun hasil wawancara sebagai berikut:

"Peningkatan teknik untuk atlet saya terjadi peningkatan, teknik yang sempurna akan membawa atlet lebih mudah berprestasi apalagi kalau ada nomor seni di Pencak Silat” (Ni Putu Spyanawati, Pelatih Pencak Silat).

"Teknik saya lumayan meningkat akibat dari proses latihan tersebut, saya dapat tehnik guntingan yang baru dan sangat Baik diterapkan saat berlomba " (Sutiani, Etlet Pencak Silat).

"Perbaikan teknik sangat dirasakan tahun 2001-2005 saya menggunakan teknik gaya ortodok, 2005- sekarang saya menggunakan gaya obrain yang secara teori lebih baik untuk mendapatkan tolakan yang maksimal latihan obrain sendiri adalah saat saya menjadi atlet PPLM" (Nita Wijayanti, Alumni Atlet Atletik Tahun 2006-2009).

Berdasarkan wawancara dengan pelatih, mantan pelatih, atlet dan alumni atlet PPLM Bali, terungkap bahwa peningkatan dari sisi teknik sangat dirasakan oleh atlet, peningkatan teknik sangat menunjang penampilan saat berlomba/bertanding. Berdasarkan hasil wawancara, studi dokumen dan studi lapangan dapat disimpulkan bahwa atlet PPLM di Bali mengalami peningkatan keterampilan tekni dengan sangat baik.

\section{C.Prestasi Atlet}

Prestasi atlet lebih menitikberatkan pada pencapaian prestasi yang diwujudkan dalam bentuk perolehan medali pada setiap kejuaraan yang diikuti atlet-atlet PPLM Bali. Adapun hasil wawancara sebagai berikut:

"Prestasi yang pernah diraih adalah pada kejuaraan PPLM di Surabaya tahun 2013, yaitu 4 emas, 2 perak dan 1 perunggu, kalau di tahun 2014 cabang atletik tidak memperoleh medali karena atlet telah menjadi alumni” (I Nyoman Sudarmada, Pelatih Atletik) 
"Di tahun 2013 kami memperoleh 1 emas, 1 perak, dan 2 perunggu dan di tahun 2014 kami memperoleh 1 perak dan 3 perunggu pada kejuaran PPLM seluruh Indonesia, " ( Ni Putu Spyanawati, Pelatih Pencak Silat).

Berdasarkan hasil wawancara dengan pelatih terungkap bahwa 1) atlet PPLM di Bali mampu memperoleh medali pada setiap kejuaraan, 2) pencapaian prestasi di setiap kejuaraan sifatnya dinamis, terkadang atlet mampu menjuarai di kompetisi tetapi belum tentu mampu menjuarai di kompetisi lain. Berdasarkan pengecekan data antara hasil wawancara, studi dokumen dapat disimpulkan bahwa atlet PPLM Bali mampu mencapai prestasi yang ditunjukkan melalui perolehan medali, terungkap juga bahwa pencapaian prestasi di setiap kejuaraan sifatnya fluktuatif dan kencendrungan menurun. Adapun hasil perolehan prestasi olahraga atlet sebagai berikut:

\section{Tabel 1. Perolehan Medali PPLM Bali Di Kejuaraan Nasional}

\begin{tabular}{cccccccc}
\hline \multirow{2}{*}{ No } & TAhUN & TEMPAT & CABANG & MEDAli & RANGing \\
\hline 1 & 2007 & SEMARANG & ATLETIK & 1 & 1 & 1 & 10 \\
2 & 2008 & JAKARTA & ATLETIK & 1 & - & 1 & 13 \\
3 & 2009 & SURABAYA & $\begin{array}{c}\text { ATLETIK } \\
\text { DAN SILAT }\end{array}$ & 1 & 3 & 2 & 11 \\
4 & 2010 & BANDUNG & ATLETIK & 1 & - & 1 & 12 \\
5 & 2011 & SOLO & $\begin{array}{c}\text { ATLETIK } \\
\text { DAN SILAT }\end{array}$ & 3 & 1 & 6 & 7 \\
6 & 2012 & SOLO & $\begin{array}{c}\text { ATLETIK } \\
\text { DAN SILAT }\end{array}$ & 3 & 1 & 2 & 8 \\
7 & 2013 & SURABAYA & $\begin{array}{c}\text { ATLETIK } \\
\text { DAN SILAT }\end{array}$ & 5 & 3 & 3 & 3 \\
8 & 2014 & JAKARTA & $\begin{array}{c}\text { ATLETIK } \\
\text { DAN SILAT }\end{array}$ & - & 1 & 3 & 12 \\
\hline
\end{tabular}

Selanjutnya data di atas secara lebih rinci dapat dijelaskan dalam diagram batang di bawah ini:

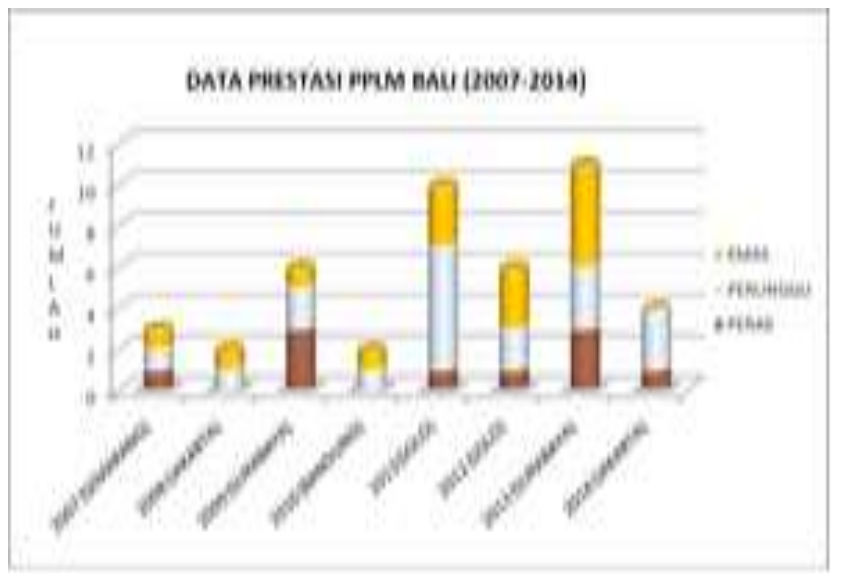

Gambar 1. Diagram Prestasi PPLM Bali (2007-2014)

\section{Simpulan dan Rekomendasi}

Evaluasi program Pusat Pendidikan dan Latihan Olahraga Mahasiswa (PPLM) Bali adalah proses pengambilan data yang sistematis untuk melakukan penilaian dan pengambilan keputusan terhadap suatu program dengan memperhatikan prinsip utilitas, kepatutan, kelayakan dan akurasi pada sistem pengelolaan PPLM melalui evaluasi yang telah dilaksanakan dengan pendekatan evaluasi Product. Berdasarkan hasil temuan dan pembahasan, maka dapat disimpulkan bahwa 1) Atlet PPLM Bali mengalami peningkatan kebugaran fisik, b) Atlet PPLM Bali juga mengalami peningkatan keterampilan teknik, c) Atlet PPLM Bali mampu perolehan medali pada kejuaraan dengan jumlah yang beragam dan fluktuatif namun cendrung menurun.

Berdasarkan kesimpulan di atas, maka secara umum keberlanjutan program PPLM layak untuk dilanjutkan, dan secara khusus dapat direkomendasikan antara lain: 1) Meningkatkan pembuatan perencanaan latihan seperti program latihan, administrasi dan jadwal try out-try in secara jelas dan lengkap serta menginformasikannya kepada atlet dan pelatih serta pengurus. 2) Meningkatkan kualitas latihan fisik melalui metode yang spsesifik dan sesuai dengan prinsip-prinsip latihan.

\section{REFERENSI}

Arikunto, Suharsimi, Cepi Safruddin Abdul Jabbar. (2009) Evaluasi Program Pendidikan, Jakarta: Bumi Aksara.

Cholik, M Toho dan Maksum, Ali. (2007) Sport Development Index, Jakarta: PT Indeks.

Guiterrez.AJ, (2007). Assesing Physical Ability and Its Relationshio With Health, Journal of Human Sport and Exercise, Vol 2, No 2, pp 53-71

Kemenpora. (2014). Pedoman Penyelenggaraan Pusat Pendidikan dan Latihan Olahraga Mahasiswa (PPLM). Jakarta: Kemenpora.

Marques.A, Martins.J,Sarmento.H, Diniz.J, \& Costa, FCD. (2014). Adolescents' Physical Activity Profile According To Parental Physical Activity Participation, Journal of Human Sport and Exercise, Vol 9, No 1, pp 81-90

Mattes.K, Habermann.N,Schaffert.N, \& Muhlbach.T. (2014). A Longitudinal Study Of Kinematic Stride Characteristics In Maximal Sprint Running, Journal of Human Sport and Exercise, Vol 9, No 3, pp 686699

Patilima, Hamid. (2005). Metode Penelitian Kualitatif. Bandung: Alfabeta.

Silalahi, Ulber. (2010). Metode Penelitian Sosial, Jakarta: PT Refika Aditama:

Stufflebeam, Daniel L, Anthony J Shinkfield. (2007). Evaluation Teory, Models and Applications, San Francisco: Jossey-Bass.

Subana, M dan Sudrajat. (2005). Dasar-dasar Penelitian Ilmiah. Bandung: Pustaka Setia.

Undang-Undang Nomor 3 Tahun. (2005). Sistem Keolahragaan Nasional . Jakarta: Menegpora.

Usman, Husaini,, Purnomo Setiadi Akbar. (2008). Pengantar Statistika. Jakarta: Bumi Aksara. 